\title{
Contribution of Nuclear BCL10 Expression to Tumor Progression and Poor Prognosis of Advanced and/or Metastatic Pancreatic Ductal Adenocarcinoma by Activating NF-kB-Related Signaling
}

\author{
Sung-Hsin Kuo \\ National Taiwan University Hospital \\ Shih-Hung Yang \\ National Taiwan University Hospital \\ Ming-Feng Wei \\ National Taiwan University Hospital \\ Hsiao-Wei Lee \\ National Taiwan University Hospital \\ Yu-Wen Tien \\ National Taiwan University Hospital \\ Ann-Lii Cheng \\ National Taiwan University Hospital \\ Kun-Huei Yeh ( $\square$ khyeh@ntu.edu.tw) \\ National Taiwan University Hospital https://orcid.org/0000-0002-7306-174X
}

Primary research

Keywords: Pancreatic cancer, BCL10, NF-KB, Prognosis

Posted Date: May 5th, 2021

DOI: https://doi.org/10.21203/rs.3.rs-452604/v1

License: (c) (1) This work is licensed under a Creative Commons Attribution 4.0 International License. Read Full License

Version of Record: A version of this preprint was published at Cancer Cell International on August 19th, 2021. See the published version at https://doi.org/10.1186/s12935-021-02143-z. 


\section{Abstract \\ Background:}

We previously demonstrated that nuclear BCL10 translocation participates in the instigation of NF-KB in breast cancer and lymphoma cell lines. In this study, we assessed whether nuclear BCL10 translocation is clinically significant in advanced and metastatic pancreatic ductal adenocarcinoma (PDAC).

\section{Method and materials:}

We analyzed the expression of BCL10-, cell cycle-, and NF-KB- related signaling molecules, and the DNAbinding activity of NF-KB in three PDAC cell lines (mutant K-RAS lines: PANC-1 and AsPC-1; wild-type KRAS line: BxPC-3) using BCL10 short hairpin RNA (shBCL10). To assess the anti-tumor effect of BCL10 knockdown in PDAC xenograft model, PANC-1 cells treated with or without shBCL10 transfection were inoculated into the flanks of mice. We assessed the expression patterns of BCL10 and NF-KB in tumor cells in 136 patients with recurrent, advanced, and metastatic PDAC using immunohistochemical staining.

\section{Results:}

We revealed that shBCL10 transfection caused cytoplasmic translocation of BCL10 from the nuclei, inhibited cell viability, and enhanced the cytotoxicities of gemcitabine and oxaliplatin in three PDAC cell lines. Inhibition of BCL10 differentially blocked cell cycle progression in PDAC cell lines. Arrest at G1 phase was noted in wild-type K-RAS cell lines; and arrest at G2/M phase was noted in mutant K-RAS cell lines. Furthermore, shBCL10 transfection downregulated the expression of Cdc2 (PANC-1), cyclin D1 (BxPC-3), p-IKBa, nuclear expression of BCL10, BCL3, and NF-KB (p65), and attenuated the NF-KB pathway activation and its downstream molecule, c-Myc. In a PANC-1-xenograft mouse model, inhibition of BCL10 expression also attenuated the tumor growth of PDAC. In clinical samples, nuclear BCL10 expression was closely associated with nuclear NF-KB expression $(p<0.001)$, and patients with nuclear BCL10 expression had the worse median overall survival than those without nuclear BCL10 expression (6.90 months versus 9.53 months, $p=0.019$ ).

\section{Conclusion:}

Nuclear BCL10 translocation activates NF-KB signaling and contributes to tumor progression and poor prognosis of advanced/metastatic PDAC.

\section{Introduction}


The majority of patients with pancreatic ductal adenocarcinoma (PDAC) are diagnosed when the cancer becomes un-resectable and metastatic [1,2]. The median survival for patients with locally advanced PDAC, who received combined chemotherapy and radiotherapy or chemotherapy alone, varies from 7 to 21 months [3, 4]. However, the median survival for patients with metastatic PDAC is approximately 3-6 months after treatment with single-agent or combinational chemotherapy, or with targeted therapy $[4,5]$. In contrast to the efficacies of epidermal growth factor receptor- or vascular endothelial growth factortargeting agents in many solid tumors, aforementioned molecular targeted agents exhibit limited therapeutic efficacies in patients with PDAC [6-8].

Tumor microenvironments, for example, pancreatic stellate cells (main components of the stroma) can promote the proliferation, invasion, metastasis, and drug resistance of pancreatic cancer cells $[9,10]$. Previous studies have demonstrated that sonic hedgehog (Shh) ligands facilitate cell proliferation of PDAC through triggering nuclear factor (NF)-KB $[11,12]$. Our previous work showed that nuclear expression of NF-KB or Gli1 (a determinant of Shh signaling) was associated with poor overall survival (OS) of patients with advanced and metastatic PDAC after commencing chemotherapy [13]. These findings suggested that proinflammatory cytokines or growth factors can activate NF-KB signaling in stromal or cancer cells of PDAC though autocrine or paracrine loop.

BCL10 (B-cell CLL/lymphoma 10), cloned from the $t(1 ; 14)(p 22 ; q 32)$, is involved in the pathogenesis of mucosa-associated lymphoid tissue (MALT) lymphoma [14, 15]. When BCL10 is expressed in the cytoplasm of normal $T$ and $B$ cells, it communicates antigen receptor mediated signals and further activates NF-KB signaling $[16,17]$. We have previously reported that nuclear translocation and colocalization of BCL10 and NF-KB are closely associated with antibiotic-unresponsiveness of gastric MALT lymphoma $[18,19]$. In human breast cancer cells (MCF7 cell lines), we revealed that AKT, activated by tumor necrosis factor-alpha (TNF-a), phosphorylates BCL10 at Ser ${ }^{218}$ and $\operatorname{Ser}^{231}$, which subsequently forms a complex with BCL3 (containing a nuclear localization signal) to enter the nucleus and further activate NF-KB signaling [20]. Furthermore, we reported that BCL10 regulates tumor cell growth of cervical cancer cells by regulating the activation of NF-KB-dependent cyclin D1 signaling [21]. These results revealed an association between nuclear BCL10 translocation and the activation of NF-KB in certain subtypes of solid cancers. However, little is known about the biological characteristics of BCL10 in PDAC, although the expression of BCL10 has previously been reported in pancreatic acinar cell cancer [22].

Considering that NF-KB activation has been shown to be associated with the pathogenesis and prognosis of PDAC $[13,23,24]$, we sought to investigate whether BCL10 signaling and its association with NF-KB activation possesses any clinical significance with respect to PDAC. We first assessed the BCL10mediated regulation of cell proliferation and activation of NF-KB in PDAC through both in vitro and in vivo models. Subsequently, we examined the association between nuclear BCL10 expression patterns in tumor cells and the clinical outcomes of patients with recurrent, advanced, and metastatic PDAC who received systemic chemotherapy.

\section{Methods And Materials}




\section{Pancreatic cancer cell lines}

The human PDAC cell lines, PANC-1 (mutant K-RAS), AsPC-1 (mutant K-RAS), and BxPC-3 (wild type KRAS), were purchased from American Type Culture Collection (ATCC). The PANC-1 cell line was maintained in complete Dulbecco's modified Eagle's medium (DMEM), whereas AsPC-1 and BxPC-3 were maintained in complete Roswell Park Memorial Institute (RPMI)-1640. Furthermore, all cell lines were cultured in an incubator containing a humidified atmosphere and $5 \% \mathrm{CO}_{2}$ at $37^{\circ} \mathrm{C}$.

\section{The shRNA-mediated BCL10 silencing in PDAC cell lines}

Previously, we demonstrated that TNF-a expression resulted in the BCL10 nuclear translocation due to phosphorylation of BCL10 Ser ${ }^{218}$ or Ser ${ }^{231}$ in MCF7 cells [20]. The short hairpin RNA (shRNA)-expression lentiviral vector of BCL10 (TRCN0000359256) was obtained from the National RNAi Core Facility (Taipei, Taiwan), and the silenced site was located in the Ser ${ }^{231}$ of BCL10 (Supplementary Fig. 1). For construction of the lentiviruses, BCL10 shRNA transfected (shBCL10) vectors, psPAX2 (Addgene), and pMD2.G (Addgene), were cotransfected into 293T cells. At $48 \mathrm{~h}$ after transfection, the supernatant was collected and used to infect the three PDAC cell lines. The pGIPZ lentiviral vector (Fisher Scientific) was used as a scrambled control.

\section{Cell proliferation and cytotoxicity assay}

The PDAC cells with or without transfection of shBCL10 lentivirus were seeded into 96-well plates at a density of 1000 cells/well. Every two days, the levels of cell proliferation were assessed using a Premixed WST-1 Cell Proliferation Reagent (Clontech). The absorbance was detected at $450 \mathrm{~nm}$ against the background control using a multi-well plate reader. The cell proliferation rate was calculated as follows: Proliferation rate $=($ absorbance $/$ absorbance of Day 1$) \times 100 \%$. The results are revealed as the mean \pm standard error (SE) of three different experiments.

For cytotoxicity assay, cells were seeded into 96-well plates at a density of 3000 cells/well, and then, treated with oxaliplatin and gemcitabine at various doses. After incubation at $37^{\circ} \mathrm{C}$ for $72 \mathrm{~h}$, cell viability was also measured using Premixed WST-1 Cell Proliferation Reagent. The data are expressed as the

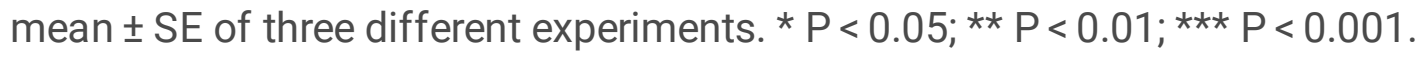

\section{Flow cytometric analysis}

The untransfected, scramble shRNA (Scr) transfected, and shBCL10 transfected PDAC cells seeded into 6 -cm dishes were detached using $0.05 \%$ trypsin-EDTA (Gibco). The harvested cells were washed twice with phosphate buffered saline (PBS), and then, fixed in $70 \%$ cold ethanol at $4^{\circ} \mathrm{C}$ overnight. Fixed cells were washed twice with PBS, incubated with $50 \mu \mathrm{g} / \mathrm{ml} \mathrm{RNase}$ at $37^{\circ} \mathrm{C}$ for $30 \mathrm{~min}$, and stained with propidium iodide (PI) $(50 \mu \mathrm{g} / \mathrm{mL})$ on ice for $30 \mathrm{~min}$. The cell cycle phases of stained cells were analyzed in the FL-2 channel using a FACSCalibur (Becton Dickinson, BD FACSCalibur ${ }^{\text {TM }}$ system).

\section{Confocal immunofluorescence}


The shBCL10 untreated and treated PDAC cells were plated on cell culture slide (SPL Life Sciences) overnight. After washing twice with PBS, the cells fixed with $3.7 \%$ paraformaldehyde at $4^{\circ} \mathrm{C}$ for 8 min, permeabilized with $0.1 \%$ TritonX-100 in PBS for 10 min, and blocked with $3 \%$ BSA at room temperature for $1 \mathrm{~h}$. Then, cells were incubated with the anti-BCL10 primary antibody (1:200) (sc-9560; Santa Cruz Biotechnology, Santa Cruz, CA, USA) overnight. Subsequently, the cells were washed with PBS and incubated with DyLight 488 conjugated secondary antibody (1:1000) (Thermo Fisher Scientific) for 1 hour. Nuclei were counterstained with DAPI (dilution 1:1000 in PBS) (Biotium, 40043) for $5 \mathrm{~min}$. The stained cells were examined using a confocal laser scanning microscope (TCS SP5, Leica Microsystems) and a Leica Application Suite 2.02.

\section{Immunoblotting analysis}

Whole cell lysates and nuclear lysates of PADC cells were harvested from each cell subclones. Equal amounts of protein extracts were fractionated on sodium dodecyl sulfate (SDS)-Tris glycine polyacrylamide gel electrophoresis (PAGE) gel and then electrophoretically transferred to polyvinylidene difluoride (PVDF) membrane (Millipore). Primary antibodies against the following molecules were used for the analysis: BCL10 (sc-9560; Santa Cruz Biotechnology, Santa Cruz, CA, USA), BCL3 (sc-185; Santa Cruz Biotechnology), phospho (p)-IкBa (Thr ${ }^{389}$; \#2905; Cell Signaling Technology), NF-kB (p65; \#9451; Santa Cruz Biotechnology), p-p65 (Ser ${ }^{536}, 93 \mathrm{H} 1$; Cell Signaling Technology), c-Myc (sc-40; Santa Cruz Biotechnology), Cdc2 (\#28439; Cell Signaling Technology), cyclin D1 (\#2972; Cell Signaling Technology), cyclin B1 (sc-752; Santa Cruz Biotechnology), cyclin D3 (sc-182; Santa Cruz Biotechnology), cyclin E (sc9566; Santa Cruz Biotechnology), $\beta$-actin (A5316, Sigma-Aldrich, MO, USA), and a-tubulin (CP06, Calbiochem, San Diego, CA, USA) $[19,21]$. The specific reactive bands on membranes were probed using appropriate secondary IgG antibodies conjugated to horse radish peroxidase. The immune complexes were visualized using an enhanced chemiluminescence detection system (ECL, Boehringer Mannheim, Mannheim) and quantification was performed using the Image Quant software (GE Healthcare). All experiments were repeated at least three times.

\section{Luciferase assays}

For the NF-KB promoter analysis, PANC-1 and BxPC-3 cells were transfected with $5 \mu \mathrm{g}$ of NF-kB-Luc reporter plasmid DNA (BD Bioscience, Clontech, Palo Alto, CA, USA) for 6 h by using Transfast Transfection Reagent (Promega, Madison, WI, USA). The luciferase activity of the cell lysates was measured according to the luciferase assay kit manual (Promega) and normalized for the amount of protein in each cell lysate $[19,21]$.

\section{In vivo animal experiments}

Male NOD.CB17-Prkdc ${ }^{\text {scid }}$ mice were purchased from the National Laboratory Animal Center, Taiwan. Our animal experimental procedures were approved by the National Taiwan University College of Medicine and College of Public Health Institutional Animal Care and Use Committee (IACUC; Number 20150056). Approximately $1 \times 10^{6}$ scrambled PANC-1 cells and shBCL10-transfected PANC-1 cells were injected subcutaneously into the flanks of mice; and all mice received anesthesia with isoflurane/oxygen $(2.5 \%$ 
isoflurane) for 5 minutes during injection of PANC-1 cells. Body weight and tumor volumes of mice were observed after implantation and measured once a week. Tumor volume was measured with calipers and calculated using the equation: $0.5 \times L \times W^{2}$, where $L$ is the length and $W$ is the width. At the endpoint of animal experiment, all mice were euthanized with asphyxiation using carbon dioxide $\left(\mathrm{CO}_{2}\right)$ which introduced into the chamber at the rate of $30 \%$ replacement of chamber air per minute.

\section{Patients, tumor samples, and immunohistochemical analyses}

In order to reduce underlying drug resistance of different chemotherapies of bios, and the different chemotherapy regimen-associated responses and subsequent survival, we selected patients who received gemcitabine-based chemotherapy as first-line treatment after initial diagnosis of locally advanced and metastatic PDAC or at the status of recurrent and/or distant metastatic PDAC after curative surgery. Patients who were diagnosed only by cytological examination were excluded. We reviewed the medical records and histopathological data of patients with PDAC who met the aforementioned criteria. This cohort included adequate amounts of archival tissues, including biopsy or surgery (recurrent cases) for immunohistochemical evaluation, complete medical records documenting the disease course, and the histological diagnosis of PDAC. The study was approved by the Research Ethical Committee of National Taiwan University Hospital (Institutional. Review Board Number:201507023RINA).

Formalin-fixed, paraffin-embedded tumor tissue sections ( $4 \mu \mathrm{m}$ thick) were immunohistochemically stained using an avidin-biotin-peroxidase method as described previously [13]. The primary antibodies and their dilutions were as follows: anti-BCL10 (sc-9560; Santa Cruz Biotechnology) and anti-NF-KB p65 (sc-109, Santa Cruz Biotechnology). BCL10 and NF-KB nuclear expression were considered positive when more than $10 \%$ of tumor cells exhibited positively stained nuclei $[13,18]$.

\section{Statistical analysis}

The data from the WST-1 assays and cell cycle analysis are expressed as the mean \pm SE of experiments repeated at least three times. Statistical analysis was determined using Student's $t$ test, $X^{2}$ test, and Fisher's exact test. The OS was measured from the date of the commencement of chemotherapy to the date of death from any cause or the last follow-up date. Univariate analysis was performed using KaplanMeier survival curves (log-rank test) to evaluate the statistical significance of OS differences among patients with tumors either or not expressing nuclear BCL10. A p value of $<0.05$ was considered statistically significant.

\section{Results}

\section{Downregulation of BCL10 attenuates the proliferation of PDAC cells}


To investigate the functions of BCL10 in PDAC cells, we first validated the localization of BCL10. The three PDAC cell lines were infected with BCL10 shRNA lentivirus, and then, assessed by western blot analysis. The data showed efficient knockdown of BCL10 after transfection with BCL10 shRNA (Fig. 1a). The immunofluorescence image from confocal microscopy showed that BCL10 was localized in nucleus and cytoplasm of all three PDAC cell lines (PANC-1, AsPC-1, and BxPC-3) (Fig. 1b). After transfection with BCL10 shRNA (shBCL10), the fluorescence intensity of BCL10 in cytoplasm and nucleus was markedly reduced in BXPC-3 cells, and BCL10 expression was mainly restricted to cytoplasm in PANC-1 and AsPC-1 cells (Fig. 1c).

We further examined whether the growth of PDAC cells was inhibited after BCL10 knockdown. As shown in Fig. 1c, transfection with shBCL10 significantly reduced cell proliferation in three PDAC cell lines. These results suggested that nuclear translocation of BCL10 may be a key event in the promotion of proliferation of these PDAC cells.

\section{Downregulation of BCL10 causes cell cycle arrest and enhances the cytotoxicities of chemotherapeutic agents in PDAC cells}

To investigate whether BCL10-mediated suppression of proliferation of pancreatic cancer cells is via the cell cycle arrest, we assessed the effects of shBCL10 transfection on cell cycle regulation in three PDAC cell lines. As shown in Fig. 2a, in K-RAS mutant PDAC cells, PANC-1 and AsPC-1, there was a significant increase in the number of cells in the $\mathrm{G} 2 / \mathrm{M}$ phase and significant decrease in the number of cells in the G1 phase. In the K-RAS wild-type PDAC cell line, BxPC-3, we observed that there was a significant increase in the number of cells in the $\mathrm{G} 1$ phase and significant decrease in the number of cells in the G2/M phase (Fig. 2a). These findings indicated that knockdown of BCL10 differentially inhibited cell cycle progression in PDAC cell lines; 1 1 phase arrest was noted in wild-type K-RAS cell lines, whereas G2/M phase arrest was noted in mutant K-RAS cell lines.

We further evaluated whether PDAC cells are sensitive to conventional chemotherapy after silencing of BCL10 using shBCL10. The PDAC cell lines were treated with various doses of gemcitabine and oxaliplatin for $72 \mathrm{~h}$, respectively. The cytotoxicity assay showed that BCL10-silenced cells exhibited significantly lower cell survival rate compared with scrambled cells after treatment with the same drug doses of gemcitabine (Fig. 2b) and oxaliplatin (Fig. 2c) in the three PDAC cell lines.

\section{Downregulation of BCL10 significantly decreases the expression of cell cycle-regulatory and NF-KB- related proteins, and inhibits NF-KB activation}

It has previously been demonstrated that cyclins D1 and D3 are involved in the $\mathrm{G} 1$ phase, while cyclin $\mathrm{E}$ participates in the transition to the G1/S phase [25]. In contrast to G1/S phase, Cdc2 and cyclin B1 are involved in the G2/M phase [26]. We then assessed whether cyclins D1, D3, and E, and Cdc2 in PANC-1 (mutant K-RAS) cells were affected by inhibition of BCL10; we found that the expression of Cdc2 was markedly reduced after shBCL10 transfection, while the expressions of cyclins D1, D3, and E were not affected (Fig. 3a). In contrast to PANC-1, we found that in BxPC-3 (wild type K-RAS) cells, shBCL10 
downregulated cyclin D1 expression but did not affect the expression of cyclin D3, cyclin E, and Cdc2 (Fig. 3a). These results indicated that BCL10 inhibition can result in differential cell cycle arrest in the two different pancreatic cancer cell lines: mutant K-RAS cell lines (G2/M arrest) and wild-type K-RAS cell lines (G1 arrest).

As shown in Fig. 3b, shBCL10 transfection inhibited the expression of nuclear BCL3 and p-IKBa, both of which are recognized as important regulators of NF-KB in both PANC-1 and BxPC-3 cells. In addition, shBCL10 transfection downregulated nuclear expression of NF-KB (p65) and c-Myc in both PANC-1 and BxPC-3 cells. As indicated by the results from the NF-KB-Luc promoter activity assay, the transcription of NF-kB-dependent genes, led by the nuclear translocation and DNA binding of NF-KB, was downregulated in both PANC-1 and BxPC-3 cells after transfection with shBCL10 (Fig. 3c).

To confirm the role of BCL10-mediated activation of NF-KB in cell cycle regulation, we treated PANC-1 and BxPC-3 cells with an NF-KB inhibitor, BAY117082 $(2 \mu \mathrm{M})$, for $24 \mathrm{~h}$; cell cycle distribution analysis, as shown in Fig. 3d, revealed that the inhibition of NF-KB did cause cell cycle arrest at G2/M in PANC-1 cells and at $\mathrm{G} 1$ arrest in BxPC-3 cells. As shown in Fig. 3e, we showed that expression of cyclin B1 (PANC-1), cyclin D1 (BxPC-3), and nuclear BCL10, BCL3, c-Myc, and p-p65 (both BxPC-3 and PANC-1) was downregulated after BAY117082 treatment. We concluded that BCL10, at least in part, regulates the growth of PDAC cells via NF-KB-dependent signaling.

\section{Inhibition of BCL10 expression reduces tumor growth of PDAC in a xenograft model}

To assess the anti-tumor effect of BCL10 knockdown in PDAC xenograft model, PANC-1 cells treated with or without shBCL10 transfection were inoculated into the flanks of mice. Tumor volume was recorded from appearance of initial tumor burden (Fig. 4a and 4b). When compared with scrambled group of PANC-1 xenograft tumors, we observed that the tumor growth was significantly inhibited after transfection with shBCL10 (Fig. 4a). The shBCL10-transfected group exhibited $78 \%$ reduction of tumor volume compared with scrambled group at 5 weeks (Fig. $4 \mathrm{~b}$ ). There were no significant differences in the body weight between scrambled PANC-1 group and shBCL10-transfected PANC-1 group (Fig. 4c). The nuclear expression levels of BCL10, BCL3, and NF-KB (p65) in tumor cells were also downregulated in shBCL10-transfected PANC-1 group when compared with scrambled PANC-1 group (Fig. 4d).

Nuclear expression of BCL10 in clinical sample is closely associated with the poor overall survival of patients with recurrent, advanced, and metastatic PDAC

The patients' clinical characteristics are summarized in Table 1. The median age for all the patients was 59 years old (range: $27-82$ ) and all patients had histologically confirmed PDAC. Approximately one third of the patients ( 49 of 136 cases, $36 \%$ ) had a history of smoking tobacco. Of 136 patients, 80 patients (58.8\%) were initially diagnosed with stage IV pancreatic cancer, and the most common metastatic sites were liver, whereas 19 patients had locally advanced pancreatic cancer. Of 136 patients, 37 patients had local recurrence $(n=15)$ and/or distant metastasis $(n=22)$ after undergoing surgery with curative intent. 
After a median follow-up of 24.8 months ( $95 \%$ confidence interval [Cl]: 13.2-36.4 months), the median OS after commencing chemotherapy for locally advanced and metastatic PDAC or developing recurrence and/or distant metastasis of the entire group was 7.54 months ( $95 \% \mathrm{Cl}$ : 6.11-8.98 months). 
Table 1

Clinicopathologic features between nuclear BCL10-negative and nuclear BCL10-positive groups of patients with PDAC

\begin{tabular}{|c|c|c|c|c|}
\hline & & Nuclear BC & 0 expression & \\
\hline & Total $(\mathrm{N})$ & Negative & Positive & p-value \\
\hline Number & 136 & 78 (57.4\%) & $58(42.6 \%)$ & \\
\hline Age & & & & $0.837+$ \\
\hline Median & 59.0 & 58.0 & 61.0 & \\
\hline Range & $27-82$ & $35-82$ & $27-76$ & \\
\hline Sex & & & & $0.102 \ddagger$ \\
\hline Men & $83(61.0 \%)$ & $43(55.1 \%)$ & $40(69.0 \%)$ & \\
\hline Women & $53(39.0 \%)$ & 35 (44.9\%) & $18(31.0 \%)$ & \\
\hline Smoking & & & & $0.262 \ddagger$ \\
\hline No & 87 (64.0\%) & 53 (67.9\%) & $34(58.6 \%)$ & \\
\hline Yes & $49(36 / 0 \%)$ & 25 (32.1\%) & $24(41.4 \%)$ & \\
\hline Alcohol & & & & $0.937 \ddagger$ \\
\hline No & 98 (72.1\%) & $56(71.8 \%)$ & 42 (72.4\%) & \\
\hline Yes & 38 (27.9\%) & $22(28.2 \%)$ & $16(27.6 \%)$ & \\
\hline Stage & & & & $0.743 \S$ \\
\hline Recurrent & $37(27.2 \%)$ & $23(29.5 \%)$ & $14(24.1 \%)$ & \\
\hline Stage IIIB & $19(14.0 \%)$ & $9(11.5 \%)$ & $10(17.2 \%)$ & \\
\hline Stage IV & $80(58.8 \%)$ & 46 (59.0\%) & $34(58.6 \%)$ & \\
\hline Metastases & & & & $0.667 \S$ \\
\hline Peritoneal & 12 (8.8\%) & $7(9.0 \%)$ & $5(9.6 \%)$ & \\
\hline Liver & $83(61.0 \%)$ & $47(60.2 \%)$ & $36(62.1 \%)$ & \\
\hline Other sites* & $23(16.9 \%)$ & $12(15.4 \%)$ & $11(19.0 \%)$ & \\
\hline Regional LNs & 18 (13.2\%) & $12(15.4 \%)$ & $6(10.3 \%)$ & \\
\hline Chemotherapy & & & & $0.306 \ddagger$ \\
\hline Gem-alone & $44(32.4 \%)$ & 28 (35.9\%) & $16(27.6 \%)$ & \\
\hline Gem-based & 92 (67.6\%) & 50 (61.1\%) & 42 (72.4\%) & \\
\hline
\end{tabular}




\begin{tabular}{|lllll|}
\hline \multicolumn{5}{|c|}{ Nuclear BCL10 expression } \\
\hline Response & & & $0.423 \S$ \\
\hline CR + PR & $11(8.1 \%)$ & $6(7.7 \%)$ & $5(8.6 \%)$ & \\
SD + PD & $85(62.5 \%)$ & $51(65.4 \%)$ & $34(58.6 \%)$ & \\
NA & $40(29.4 \%)$ & $21(26.9 \%)$ & $19(32.8 \%)$ & \\
NF-KB expression** & & & & $<0.001 \ddagger$ \\
Negative & $58(61.1 \%)$ & $49(84.5 \%)$ & $9(24.3 \%)$ & \\
Positive & $37(38.9 \%)$ & $9(15.5 \%)$ & $28(75.7 \%)$ & \\
\hline
\end{tabular}

The nuclear expression of BCL10 was detected in tumor cells of 58 patients (42.6\%) (Fig. 5a, b, C, and d). The difference in the demography, including age, sex, smoking history, and alcoholism were not significant between patients with nuclear BCL10 expression in tumors and those without nuclear BCL10 expression in tumors (Table 1 ). Of 136 patients, 96 patients $(70.6 \%)$ with available response to gemcitabine-based chemotherapy; however, patients without nuclear BCL10 expression did not exhibit better response (complete and partial remission) to gemcitabine-based chemotherapy than those with nuclear BCL10 expression (5/39 [12.8\%] versus 6/57 [10.5\%], $p=0.753)$. Patients with nuclear BCL10 expression had significantly worse prognoses than those without nuclear BCL10 expression (median OS after starting chemotherapy: 6.90 months [95\% Cl: 5.77-8.03] versus 9.53 months [95\% Cl: 5.89-13.18], $p=0.019)$. The 1-year OS rates for patients with nuclear BCL10 expression and for patients without nuclear BCL10 expression were 23.6\% (95\% Cl: 12.4-34.8\%) and 43.7\% (95\% Cl: 32.1-55.3\%), respectively (Fig. 5d).

Among 95 patients with available tissues to assess the expression of NF-KB (p65), we found that the nuclear BCL10 expression was significantly associated with nuclear NF-KB expression $(p<0.001$, Table 1). Similarly, patients with nuclear NF-KB expression $(n=37)$ had a shorter OS than those without nuclear NF-KB expression ( $n=58$ ) (median survival: 6.50 months [95\% Cl: $3.22-9.78$ ] versus 9.90 months [95\% Cl: 3.96-15.84], $p=0.025)$. The 1-year OS rates for patients with nuclear NF-KB expression and for patients without nuclear NF-KB expression were $31.9 \%$ (95\% Cl: $16.2-47.6 \%$ ) and $46.5 \%$ (95\% Cl: $32.6-$ $53.6 \%)$, respectively.

\section{Discussion}

In the current study, we demonstrated that inhibition of BCL10 using shBCL10 significantly inhibited the cell proliferation of the three PDAC cell lines and the tumor growth of mice bearing PANC-1 xenograft tumors. The possible mechanisms of attenuation of cell proliferation of PDAC cells via downregulation of BCL10 are through arresting of cell cycle and inactivation of NF-KB-signaling. The biological significance of nuclear BCL10 expression was further validated in tumor cells of patients with advanced, metastatic, 
and recurrent and/or metastatic PDAC after curative surgery, in which the nuclear BCL10 expression significantly correlated with nuclear NF-KB expression and poor OS (after commencing chemotherapy) of these patients.

In contrast to hematological malignancies, such as MALT lymphoma [15, 18, 19], BCL10 was rarely found in the nucleus of solid tumors [21,22]. In this study, BCL10 was expressed in cytoplasm as well as in nucleus of all three PDAC cell lines. After removal of $\operatorname{Ser}^{231}$ of BCL10, most of the BCL 10 was localized in the cytoplasm of these PDAC cell lines. In addition, nuclear expression of BCL3 was downregulated after shBCL10 treatment. Furthermore, inhibition of BCL10 by shBCL10 transfection downregulates phosphorylation of IKBa and NF-KB (p65), and attenuates NF-KB activation and its regulated protein, cMyc. In another study of natural killer T cell lymphoma, Chan et al demonstrated that interleukin 2 triggered NF-KB activation via PI3K/AKT/BCL10/BCL3 signaling pathway, and that nuclear BCL10 expression was closely associated with NF-KB activation [27]. Ismail et al also reported that in breast cancer cell line, T47D, nuclear BCL10 was subcellularly localized into the cytoplasm after transfection with siBCL10 [28]. These findings indicated that BCL10 may behave as a shuttle between nucleus and cytoplasm in certain cancer cells, and the shuttling of BCL10 may be dependent on the inflammationrelated NF-KB signaling and nuclear BCL3-associated export.

In pancreatic cancers, mutational activation of K-RAS or alterations in $\mathrm{PI} 3 \mathrm{~K}$ regulation caused by phosphatase and tensin homolog (PTEM) loss can enhance NF-KB activation and NF-kB-associated activation of downstream cytokine genes (including c-Myc and cyclin D1) [29-33], and thus, contribute to progression of these tumors. These findings were in corroboration of current study showing the vital role of nuclear BCL10 in mediating activation of the NF-KB and its downstream genes and cell cycle proteins (G1 phase arrest in K-RAS wild-type cells [cyclin D1] and G2/M phase arrest in K-RAS mutant cells [Cdc2]), and in contributing to poor prognosis. Among 75 patients with available tissue samples for analyzing KRAS mutation, we showed that nuclear BCL10 expression was not different between K-RAS wild-type and K-RAS mutant PDAC ( $p=0.557$, Supplementary Table 1$)$.

Previous studies have demonstrated that cyclin D1 overexpression is closely associated with the poor prognosis in post-operative pancreatic cancer patients [34,35]. Our previous study also reported the close association between cyclin D1 expression and nuclear BCL10 expression in cervical cancer (most cervical cancers are wild-type K-RAS) [21]. Grabocka et al. showed that silencing of HRAS or NRAS increases MAPK-RSK and PI3K-AKT signaling, and delays progression of K-RAS mutant pancreatic cancer cells through G2/M phase arrest [36]. In tissue samples, the overexpression of Cdc2 was also demonstrated to be closely associated with the lymph node metastasis, and high $\mathrm{Ki}-67$ labeling index of PDAC [37]. These findings indicated that BCL10 may play a role in regulating cell cycle in K-RAS mutant PDAC cells.

The association between nuclear BCL10 expression and patients' prognosis has been demonstrated in a variety of hematologic malignancies, including our and other investigators' studies showing Helicobacter pylori-independence (lack of tumor regression after antibiotics treatment) of gastric lymphoma [18, 19 , $38,39,40]$, the short failure-free survival in ocular adnexal MALT lymphoma [41], and locally aggressive 
tumors in cutaneous MALT lymphoma [42]. Holzmann et al reported that higher mRNA expression of BCL10 was detected in eight pancreatic cancer cell lines and in all analyzed pancreatic cancer tissues, including primary tumors and surgical margins, indicating a role of BCL10 in the molecular pathogenesis of pancreatic cancer [43].

Previous studies have demonstrated that activation of NF-KB results in significant resistance of pancreatic cancer cells to chemotherapeutic agents, including gemcitabine and oxaliplatin [24, 44]. Our in vitro study showed that inhibition of BCL10, using shBCL10, might enhance cytotoxicities of gemcitabine and oxaliplatin. Furthermore, we revealed the significant correlation between nuclear expression of BCL10 and poor OS in locally advanced and metastatic pancreatic cancer patients receiving gemcitabine-based chemotherapy. These findings indicated that BCL10 may be a potential target for treating locally advanced or metastatic pancreatic cancer.

\section{Conclusions}

In the present study, we found that BCL10 residing in the cytoplasm and nucleus of PDAC cells relays inflammation-mediated signals to activate NF-KB, and that nuclear BCL10 expression is associated with poor prognosis of patients with locally advanced and metastatic PDAC. These findings suggested that nuclear BCL10 may act as an important factor for promoting cell proliferations and chemoresistance, and thus, for increasing aggressiveness of PDAC cells. Further study of the biological significance of nuclear BCL10 in mediating NF-KB activation and in differentially regulating cell cycle proteins in PDAC cells can help us in developing novel BCL10-related therapeutic strategies for this subgroup of tumors.

\section{Abbreviations}

PDAC

pancreatic ductal adenocarcinoma; Shh:sonic hedgehog (Shh); NF-кB:nuclear factor-карра B; OS:overall survival; BCL10:B-cell CLL/lymphoma 10; TNF-a:tumor necrosis factor-alpha; ATCC:American Type Culture Collection (ATCC); RPMI:Roswell Park Memorial Institute; shRNA:short hairpin RNA; shBCL10:BCL10 shRNA transfected; SE:standard error; Scr:scrambled; Con:control; PBS:phosphate buffered saline; PI:propidium iodide; SDS:sodium dodecyl sulfate; PAGE:polyacrylamide gel electrophoresis; PVDF:polyvinylidene difluoride; p:phosphor; IACUC:Institutional Animal Care and Use Committee; Cl:confidence interval; PTEN:phosphatase and tensin homolog; RLU:relative luciferase units. GEMZAR:gemcitabine; Oxali:oxaliplatin.

\section{Declarations}

\section{Authors' contributions}

SHK participated in the experiments, analyzed the data and wrote the manuscript. SHY treated patients, analyzed data of K-RAS mutation, and provided the tissue samples of patients. MFW participated in the 
experiments, performed animal study, and analyzed the data. HWL participated in the experiments, and analyzed the data. YWT treated patients and provided the tissue samples of patients. ALC analyzed and interpreted the data. KHY designed and supervised the project. All authors have read and approved the final manuscript.

\section{Funding}

This research was funded by Ministry of Science and Technology, Taiwan, No. MOST 107-2314-B-002217-MY3, No. MOST 108-2811-B-002-616-, No. MOST 109-2314-B-002-200-, and No. MOST 109-2811-B002-565-; and National Taiwan University Hospital, Taiwan, No. NTUH 110-S4965.

\section{Availability of data and materials}

The datasets used and/or analyzed in the current study are available from the corresponding author on reasonable request.

\section{Acknowledgments:}

The authors thank the Cancer Registry, Office of Medical Records, National Taiwan University Hospital for providing the necessary patient information.

\section{Ethics approval and consent to participate}

The study was approved by the Research Ethical Committee of National Taiwan University Hospital (Institutional. Review Board Number: 201507023RINA). The animal experimental procedures were approved by the National Taiwan University College of Medicine and College of Public Health Institutional Animal Care and Use Committee (IACUC; Number 20150056).

\section{Consent for publication}

All listed authors discussed results and commented on the submitted manuscript.

\section{Competing interests}

All authors declare that they have no conflicts of interest statement.

\section{References}

1. Hidalgo M: Pancreatic cancer. N Engl J Med 2010;362(17):1605-17.

2. Kane GM, Knox JJ. Locally advanced pancreatic cancer: An emerging entity. Curr Probl Cancer. 2017:S0147-0272(17)30106-X.

3. Morganti AG, Massaccesi M, La Torre G, Caravatta L, Piscopo A, Tambaro R, et al: A systematic review of resectability and survival after concurrent chemoradiation in primarily unresectable pancreatic cancer. Ann Surg Oncol. 2010;17(1):194-205. 
4. Makris EA, MacBarb R, Harvey DJ, Poultsides GA. Surrogate End Points for Overall Survival in Metastatic, Locally Advanced, or UnresectablePancreatic Cancer: A Systematic Review and MetaAnalysis of 24 Randomized Controlled Trials. Ann Surg Oncol. 2017;24(8):2371-8.

5. Yang SH, Kuo YH, Tien YW, Hsu C, Hsu CH, Kuo SH, et al. Inferior survival of advanced pancreatic cancer patients who received gemcitabine-based chemotherapy but did not participate in clinical trials. 2011;81(3-4):143-50.

6. Merl MY, Abdelghany O, Li J, Saif MW: First-line treatment of metastatic pancreatic adenocarcinoma: can we do better? Highlights from the '2010 ASCO Annual Meeting'. Chicago, IL, USA. June 4-8, 2010. JOP. 2010;11(4): 317-20.

7. Cid-Arregui A, Juarez V. Perspectives in the treatment of pancreatic World J Gastroenterol. 2015;21(31):9297-316.

8. Hajatdoost L, Sedaghat K, Walker EJ, Thomas J, Kosari S. Chemotherapy in Pancreatic Cancer: A Systematic Review. Medicina (Kaunas).2018;54(3). pii: E48.

9. Muñoz AR, Chakravarthy D, Gong J, Halff GA, Ghosh R, Kumar AP. Pancreatic cancer: Current status and Challenges. Curr Pharmacol Rep. 2017;3(6):396-408.

10. Melstrom LG, Salazar MD, Diamond DJ. The pancreaticcancer microenvironment: A true double agent. J Surg Oncol 2017;116(1):7-15.

11. Kasperczyk H, Baumann B, Debatin KM, Fulda S. Characterization of sonichedgehog as a novel NFkappaB target gene that promotes NF-kappaB-mediated apoptosis resistance and tumor growth in vivo. FASEB J. 2009;23(1):21-33.

12. Yamasaki A, Kameda C, Xu R, Tanaka H, Tasaka T, Chikazawa N: Nuclear factor kappaB-activated monocytes contribute to pancreatic cancer progression through the production of Shh. Cancer Immunol Immunother. 2010;59(5):675-86.

13. Yang SH, Hsu CH, Lee JC, Tien YW, Kuo SH, Cheng AL. Nuclear expression of glioma-associated oncogene homolog 1 and nuclear factor-КB is associated with a poor prognosis of pancreatic cancer. 2013;85(2):86-94.

14. Willis TG, Jadayel DM, Du MQ, Peng H, Perry AR, Abdul-Rauf $M$, et al. Bcl10is involved in $t(1 ; 14)$ (p22;q32) of MALT B cell lymphoma and mutated in multiple tumor types. Cell. 1999;96(1):35-45.

15. Du MQ. MALT Iymphoma: Genetic abnormalities, immunological stimulation and molecular mechanism. Best Pract Res Clin Haematol. 2017;30(1-2):13-23.

16. Thome M, Charton JE, Pelzer C, Hailfinger S. Antigen receptor signaling to NF-kappaB via CARMA1, BCL10, and MALT1. Cold Spring Harb Perspect Biol. 2010;2(9):a003004.

17. Juilland M, Thome M. Role of the CARMA1/BCL10/MALT1 complex in lymphoid malignancies. Curr Opin Hematol. 2016;23(4):402-9.

18. Yeh KH, Kuo SH, Chen LT, Mao TL, Doong SL, Wu MS, et al. Nuclear expression of BCL10or nuclear factor kappa B helps predict Helicobacter pylori-independent status of low-grade gastric mucosaassociated lymphoid tissue lymphomas with or without $t(11 ; 18)(q 21 ; q 21)$. 2005;106(3):1037-41. 
19. Kuo SH, Tsai HJ, Lin CW, Yeh KH, Lee HW, Wei MF, et al. The B-cell-activating factor signalling pathway is associated with Helicobacter pylori independence in gastric mucosa-associated lymphoid tissue lymphoma without $t(11 ; 18)(q 21 ; q 21)$. J Pathol. 2017;241(3):420-33.

20. Yeh PY, Kuo SH, Yeh KH, Chuang SE, Hsu CH, Chang WC, et al. A pathway for tumor necrosis factoralpha-induced Bcl10 nuclear translocation. Bcl10is up-regulated by NF-kappaB and phosphorylated by Akt1 and then complexes with Bcl3 to enter the nucleus. J Biol Chem. 2006;281(1):167-75.

21. Kuo SH, Chou CH, Cheng AL, Wang CW, Chen YH, Chen RJ I. Expression of BCL10in cervical cancer has a role in the regulation of cell growth through the activation of NF-kB-dependent cyclin D1 signaling. Gynecol Oncol. 2012;126(2):245-51.

22. Hosoda W, Sasaki E, Murakami Y, Yamao K, Shimizu Y, Yatabe Y. BCL10as a useful marker for pancreatic acinar cell carcinoma, especially using endoscopic ultrasound cytology specimens. Pathol Int. 2013;63(3):176-82.

23. Weichert W, Boehm M, Gekeler V, Bahra M, Langrehr J, Neuhaus P, et al: High expression of RelA/p65 is associated with activation of nuclear factor-kappaB-dependent signaling in pancreatic cancer and marks a patient population with poor prognosis. Br J Cancer. 2007;97(4):523-30.

24. Li Q, Yang G, Feng M, Zheng S, Cao Z, Qiu J, et al. NF-kB in pancreatic cancer: Its key role in chemoresistance. Cancer 2018;421:127-34.

25. Vermeulen K, Van Bockstaele DR, Berneman ZN. The cell cycle: a review of regulation, deregulation and therapeutic targets in cancer. Cell Prolif. 2003;36(3):131-49.

26. Huang Y, Sramkoski RM, Jacobberger JW. The kinetics of $G 2$ and $M$ transitions regulated by $B$ cyclins. PLoS One. 2013;8(12):e80861.

27. Chan KK, Shen L, Au WY, Yuen HF, Wong KY, Guo T, et al. Interleukin-2 induces NF-kappaB activation through BCL10and affects its subcellular localization in natural killer lymphoma cells. J Pathol. 2010;221(2):164-74.

28. Ismail IH, Dronyk A, Hu X, Hendzel MJ, Shaw AR. BCL10is recruited to sites of DNA damage to facilitate DNA double-strand break repair. Cell Cycle. 2016;15(1):84-94.

29. Wang Z, Banerjee S, Ahmad A, Li Y, Azmi AS, Gunn JR, et al. Activated K-rasand INK4a/Arf deficiency cooperate during the development of pancreatic cancer by activation of Notch and NF- $\mathrm{K}$ signaling pathways. PLoS One. 2011;6(6):e20537.

30. Chiao PJ, Ling J. Kras, Pten, NF-кB, and inflammation: dangerous liaisons. CancerDiscov. 2011;1(2):103-5.

31. Ying H, Elpek KG, Vinjamoori A, Zimmerman SM, Chu GC, Yan H, et al. PTENis a major tumor suppressor in pancreatic ductal adenocarcinoma and regulates an NF-кB-cytokine network. Cancer 2011;1(2):158-69.

32. Asano T, Yao Y, Zhu J, Li D, Abbruzzese JL, Reddy SA. The PI 3-kinase/Akt signaling pathway is activated due to aberrant Pten expression and targets transcription factors NF-kappaB and cMycin pancreatic cancer Oncogene. 2004;23(53):8571-80. 
33. Biliran H Jr, Wang Y, Banerjee S, Xu H, Heng H, Thakur A, et al. Overexpression of cyclin D1 promotes tumor cell growth and confers resistance to cisplatin-mediated apoptosis in an elastasemyctransgene-expressing pancreatic tumor cell line. Clin Cancer 2005;11(16):6075-86.

34. Bachmann K, Neumann A, Hinsch A, Nentwich MF, El Gammal AT, Vashist Y, et al. Cyclin D1 is a strong prognostic factor for survival in pancreatic cancer: analysis of CD G870A polymorphism, FISH and immunohistochemistry. J Surg Oncol. 2015;111(3):316-23.

35. Georgiadou D, Sergentanis TN, Sakellariou S, Filippakis GM, Zagouri F, Vlachodimitropoulos D, et al. Cyclin D1, p16(INK) (4A) and p27(Kip1) in pancreaticadenocarcinoma: assessing prognostic implications through quantitative image analysis. 2014;122(12):1230-9.

36. GrabockaE, Pylayeva-Gupta Y, Jones MJ, Lubkov V, Yemanaberhan E, Taylor L, et al. Wild-type H- and $\mathrm{N}$-Ras promote mutant K-Ras-driven tumorigenesis by modulating the DNA damage response. Cancer Cell. 2014;25(2):243-56.

37. Zhou L, Li J, Zhao YP, Cui QC, Zhou WX, Guo JC, et al. The prognostic value of Cyclin B1 in pancreatic cancer. Med Oncol 2014;31(9):107.

38. Kuo SH, Chen LT, Yeh KH, Wu MS, Hsu HC, Yeh PY, et al. Nuclear expression of BCL10or nuclear factor kappa B predicts Helicobacter pylori-independent status of early-stage, high-grade gastric mucosa-associated lymphoid tissue lymphomas. J Clin Oncol. 2004;22(17):3491-7.

39. Ye H, Gong L, Liu H, Ruskone-Fourmestraux A, de Jong D, Pileri S, et al. Strong BCL10nuclear expression identifies gastric MALT lymphomas that do not respond to $\mathrm{H}$ pylori eradication. 2006;55(1):137-8.

40. Liu H, Ye H, Dogan A, Ranaldi R, Hamoudi RA, Bearzi I, et al. T(11;18)(q21;q21) is associated with advanced mucosa-associated lymphoid tissue lymphoma that expresses nuclear BCL10. 2001;98(4):1182-7.

41. Franco R, Camacho FI, Caleo A, Staibano S, Bifano D, De Renzo A, et al. Nuclear bcl10expression characterizes a group of ocular adnexa MALT lymphomas with shorter failure-free survival. Mod Pathol. 2006;19(8):1055-67.

42. Gallardo F, Bellosillo B, Espinet B, Pujol RM, Estrach T, Servitje O, et al. Aberrant nuclear BCL10expression and lack of $\mathrm{t}(11 ; 18)(\mathrm{q} 21 ; \mathrm{q} 21)$ in primary cutaneous marginal zone $\mathrm{B}$ cell lymphoma. Hum Pathol 2006;37(7):867-73.

43. HolzmannK, Kohlhammer H, Schwaenen C, Wessendorf S, Kestler HA, Schwoerer A, et al. Genomic DNA-chip hybridization reveals a higher incidence of genomic amplifications in pancreatic cancer than conventional comparative genomic hybridization and leads to the identification of novel candidate genes. Cancer 2004;64(13):4428-33.

44. Banerjee S, Kaseb AO, Wang Z, Kong D, Mohammad M, Padhye, et al. Antitumor activity of gemcitabine and oxaliplatin is augmented by thymoquinone in pancreatic cancer. Cancer Res.2009;69(13):5575-83.

\section{Figures}


a

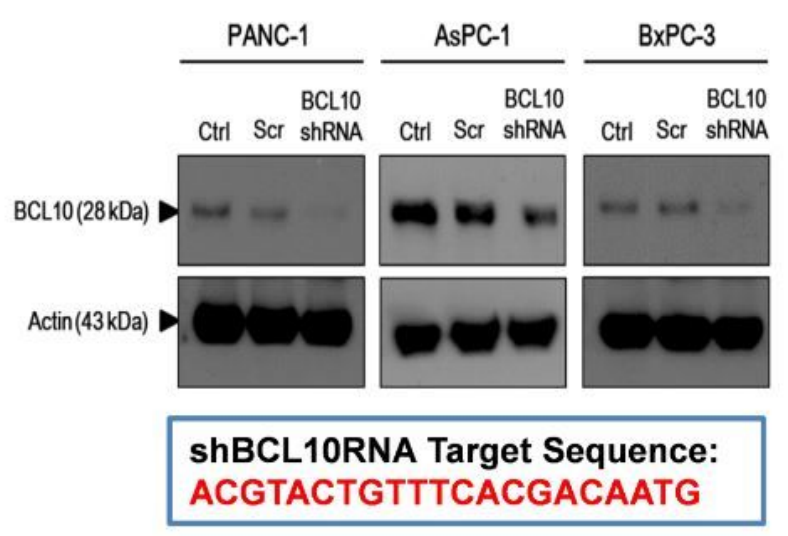

b

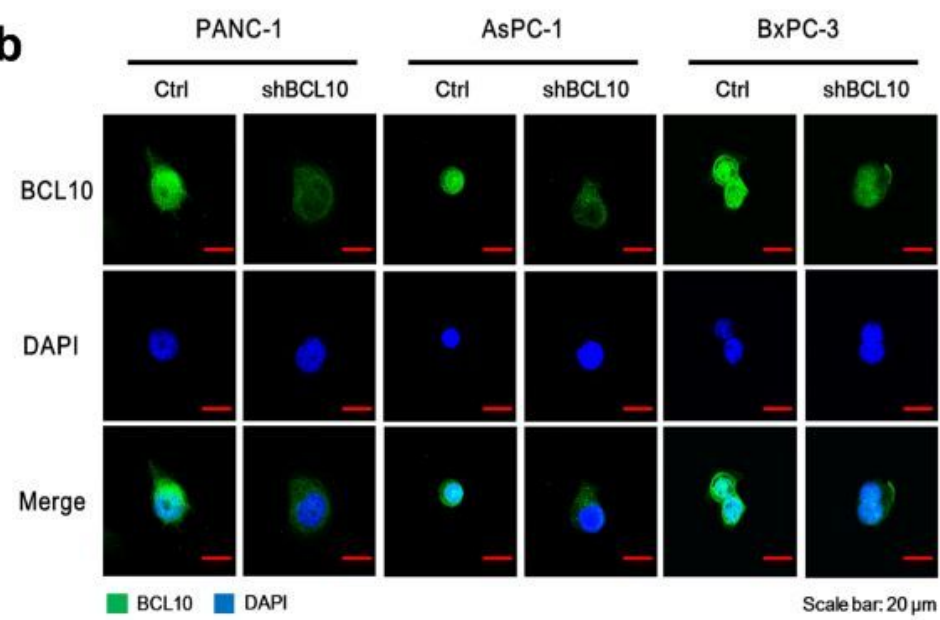

C

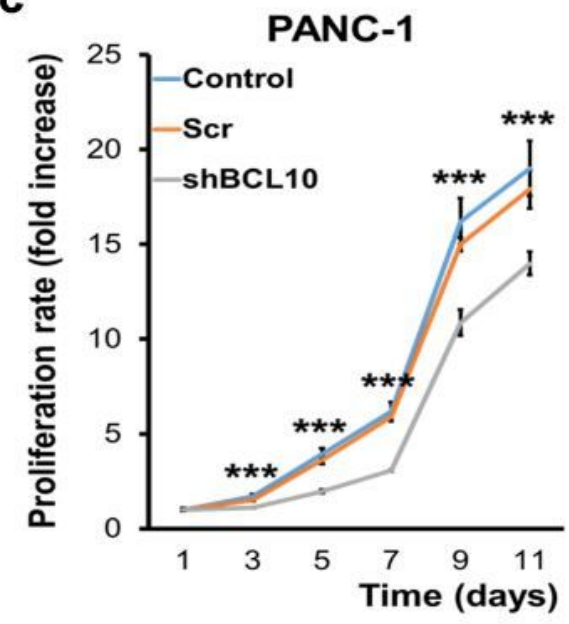

AsPC-1

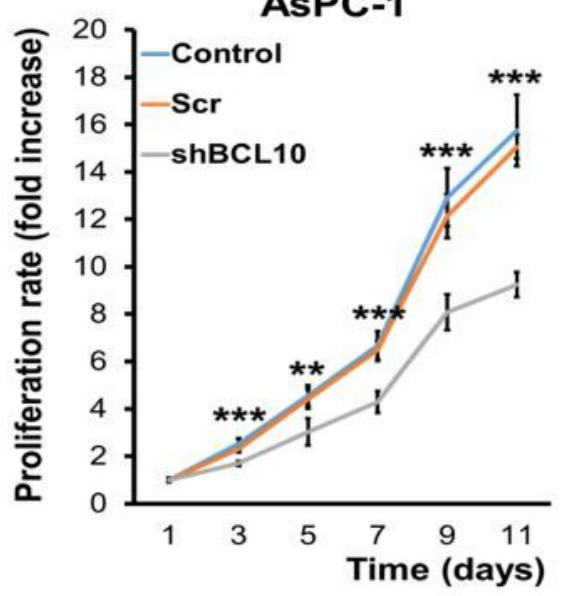

BXPC-3

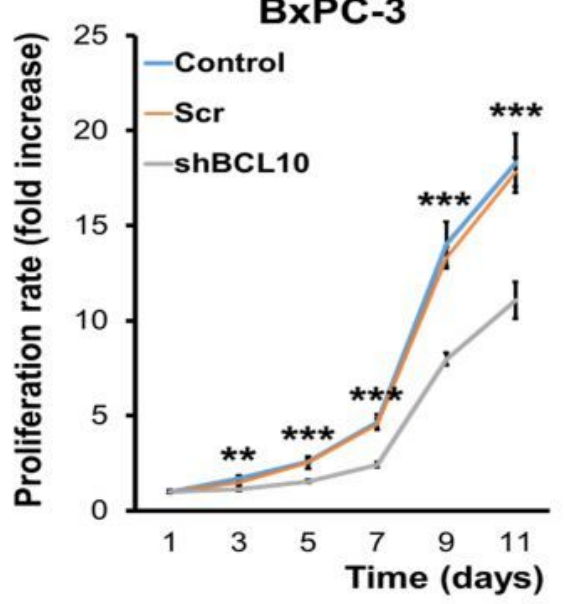

Fig. 1

\section{Figure 1}

Silencing of BCL10 in the cells of PDAC using short hairpin RNA (shRNA). a The shRNA-expression lentiviral vector of BCL10 (Clone ID: TRCN0000359256), specifically targets C-terminal region of BCL10, including Ser231 phosphorylation site (ACGTACTGTTTCACGACAATG). Three PDAC cell lines (PANC-1, AsPC-1, and BXPC-3) were infected with pGIPZ lentivirus (scrambled, Scr) and BCL10 shRNA lentivirus. The protein expression of $\beta$-actin and BCL10 was examined by western blot analysis. b Transfection with BCL10 shRNA (shBCL10) significantly decreased the levels of BCL10 in nucleus of three PDAC cell lines. Cells were labeled with anti-BCL10 primary antibody and DyLight 488 conjugated secondary antibody. The distribution of BCL10 was observed by immunofluorescence using confocal microscopy. Nuclei were counterstained with DAPI. Scale bar: $20 \mu \mathrm{m}$. c shBCL10 transfected PDAC cells exhibited low proliferative ability. The control, scrambled, and shBCL10 transfected cells from PANC-1, AsPC-1, and BxPC-3 cell lines were plated at 1000 cells/well in 96-well plate respectively. Then, cell proliferation rate was evaluated using a Premixed WST-1 Cell Proliferation Reagent after every two days. ${ }^{\star \star} p<0.01 ;{ }^{* \star} p<0.001$. PDAC, pancreatic ductal adenocarcinoma. 

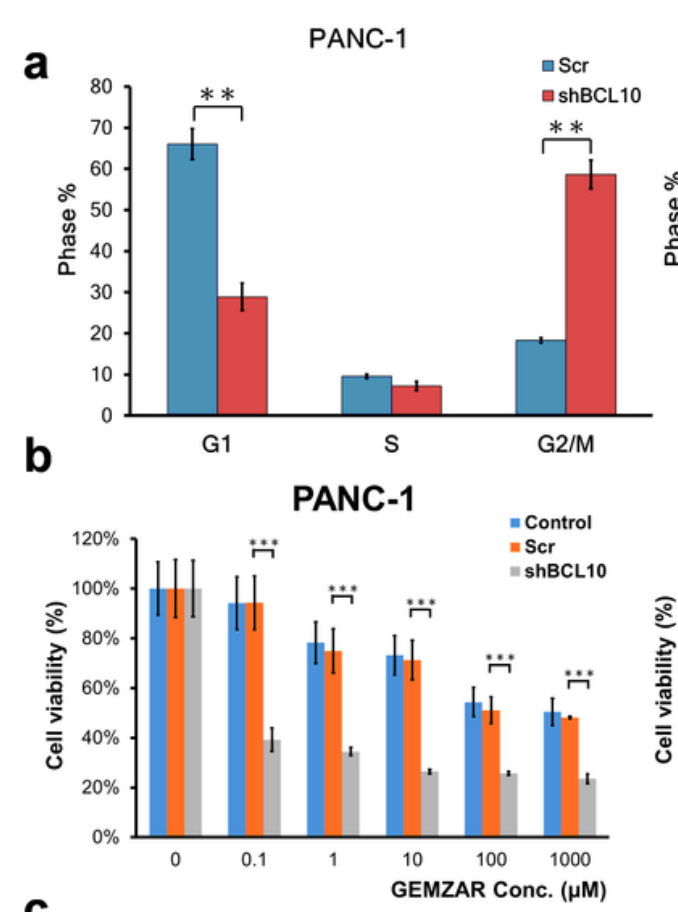

C

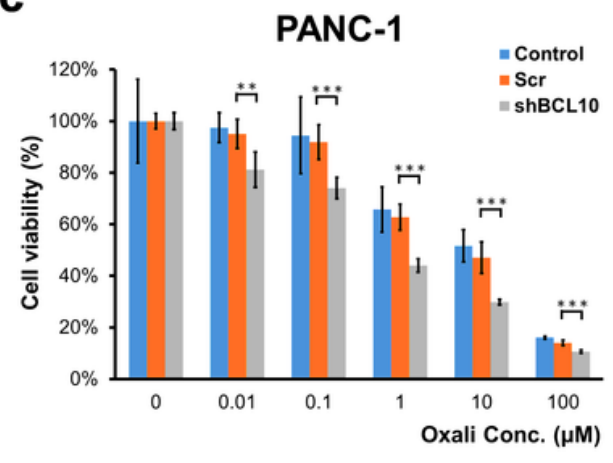

AsPC-1

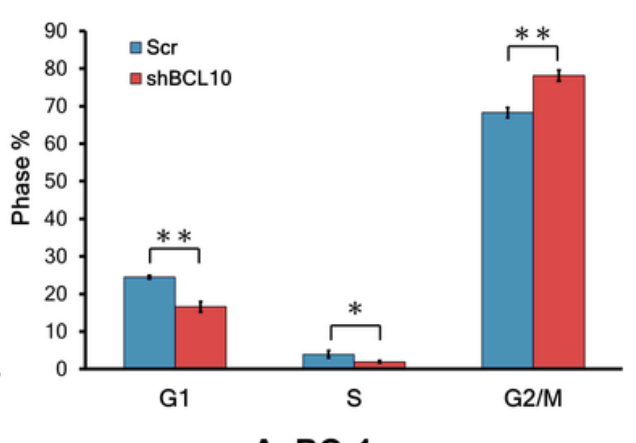

AsPC-1

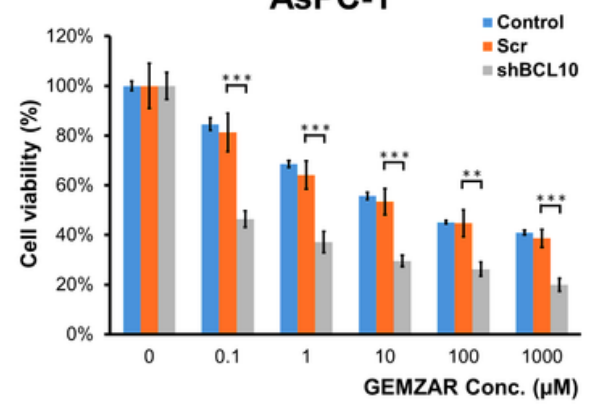

AsPC-1

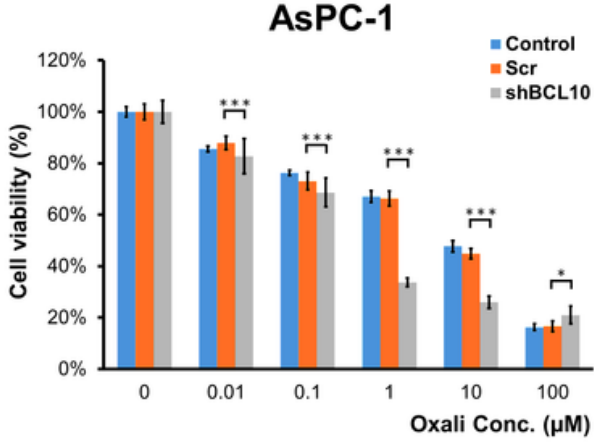

BxPC-3

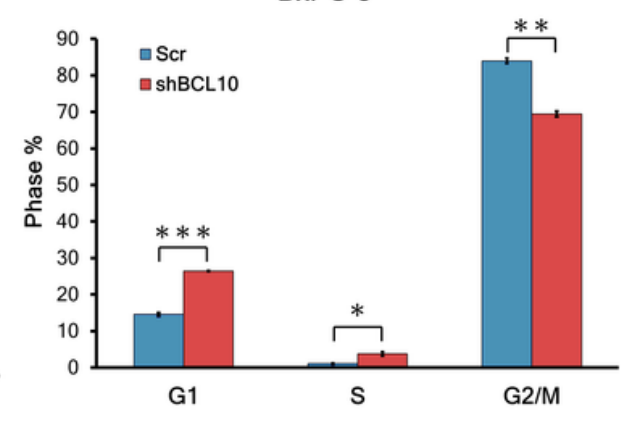

BxPC-3

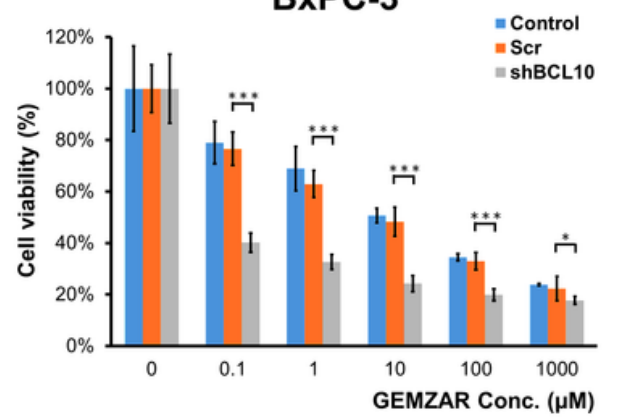

BxPC-3

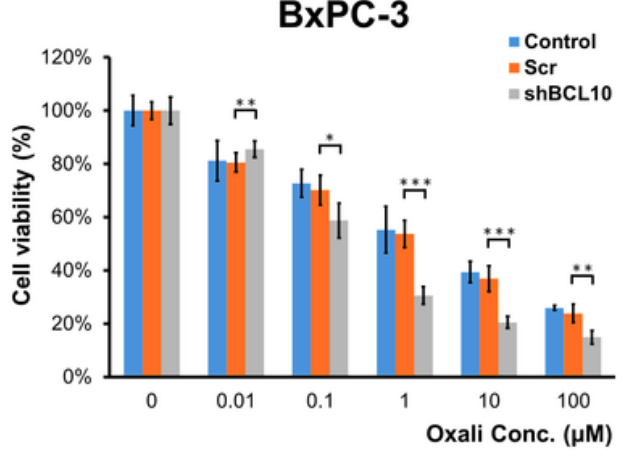

Fig. 2

Figure 2

Inhibition of BCL10 causes differential cell cycle arrest and increases drug sensitivity in PDAC cell lines. a shBCL10 resulted in G2/M phase arrest in PANC-1 and AsPC-1 cells, but caused G1 phase arrest in BxPC3. b The cell survival analysis showed that shBCL10 transfection significantly increased a dosedependent inhibition of cell viability to gemcitabine (GEMZAR) treatment in PANC-1, AsPC-1, and BxPC-3 cells. c Similarly, shBCL10 transfection significantly increased a dose-dependent inhibition of cell viability to oxaliplatin (Oxali) treatment in PANC-1, AsPC-1, and BxPC-3 cells. The results are expressed for triplicates in each treatment group and measured each week. ${ }^{*} p<0.05 ; * \star p<0.01 ; * \star \star p<0.001$. PDAC, pancreatic ductal adenocarcinoma. 
a

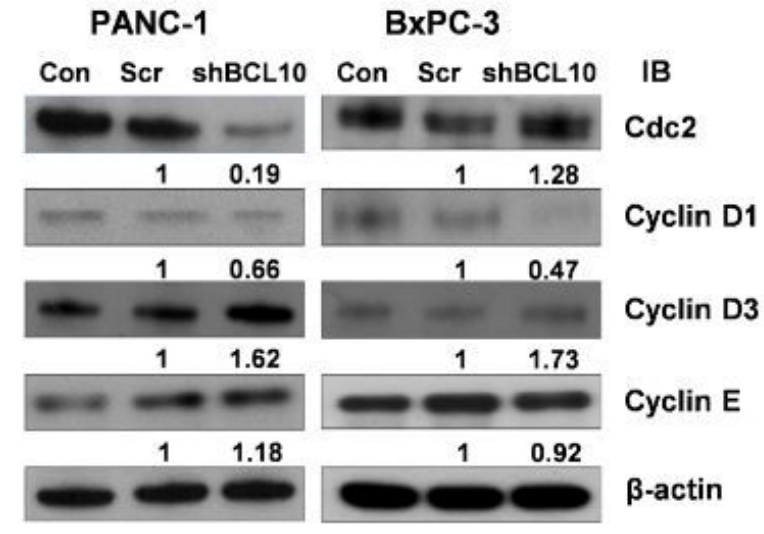

b

PANC-1
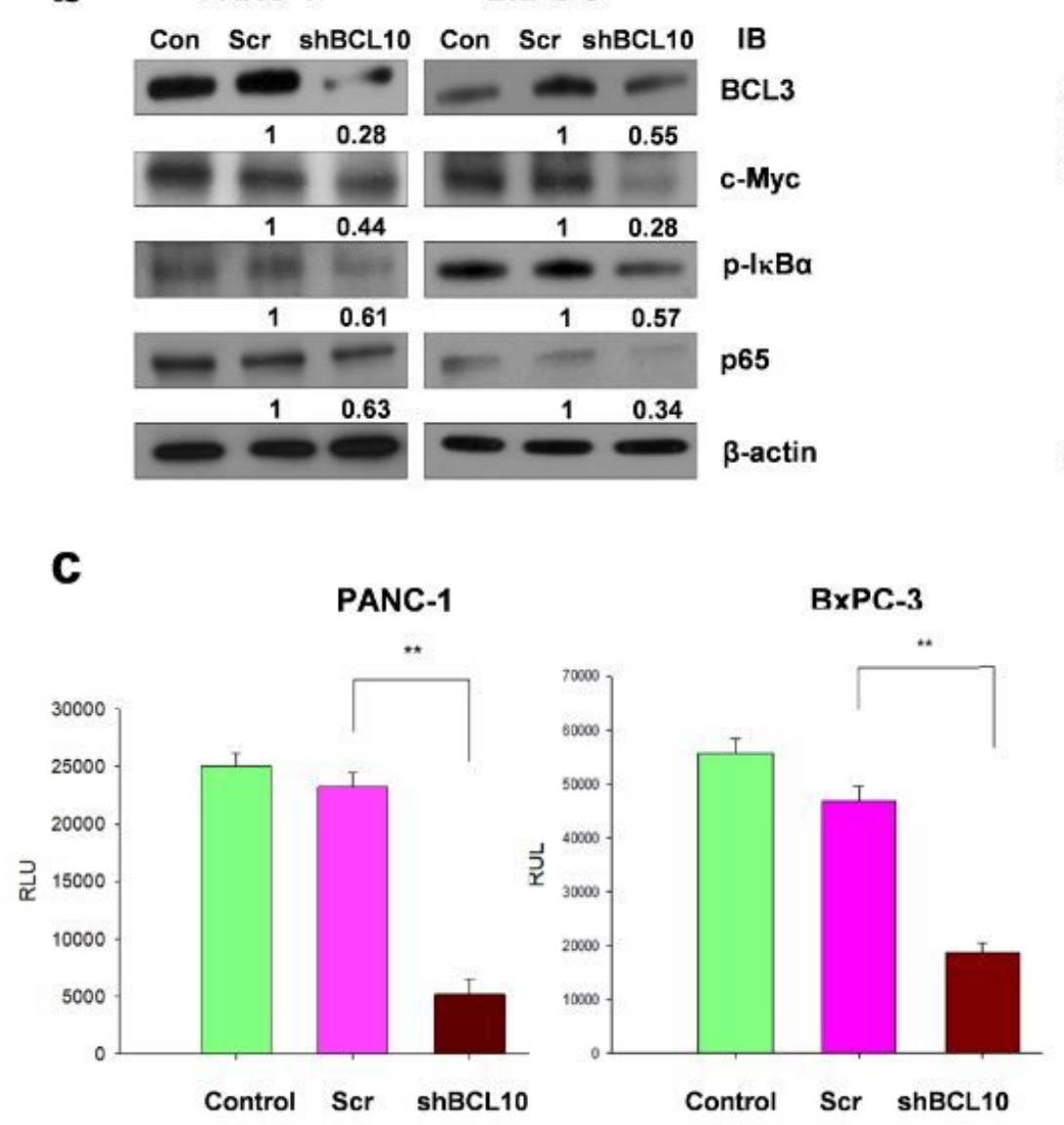

d
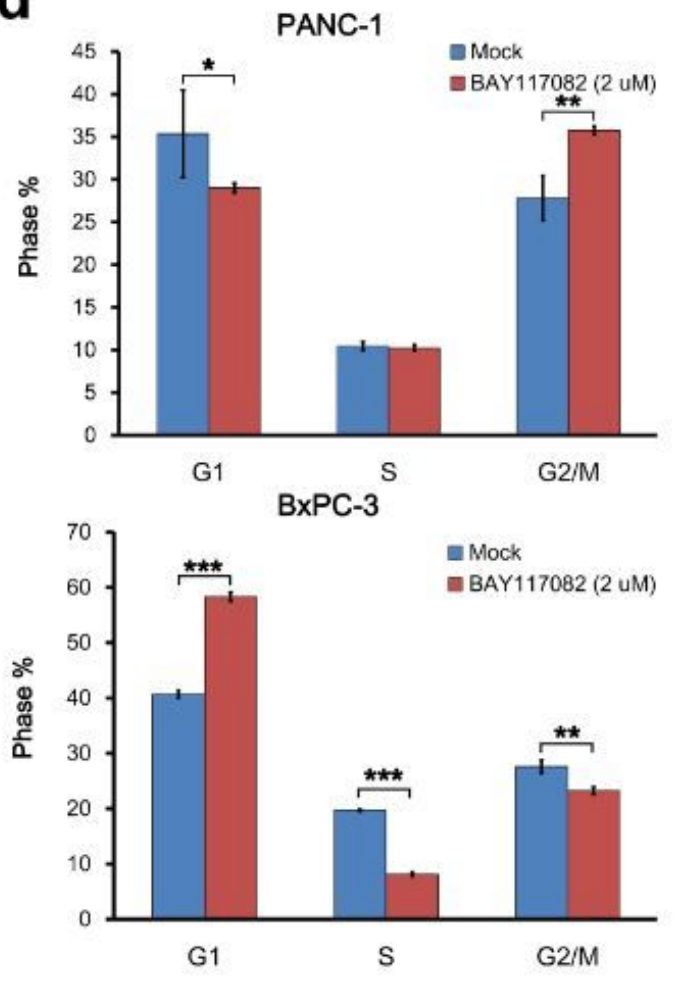

e

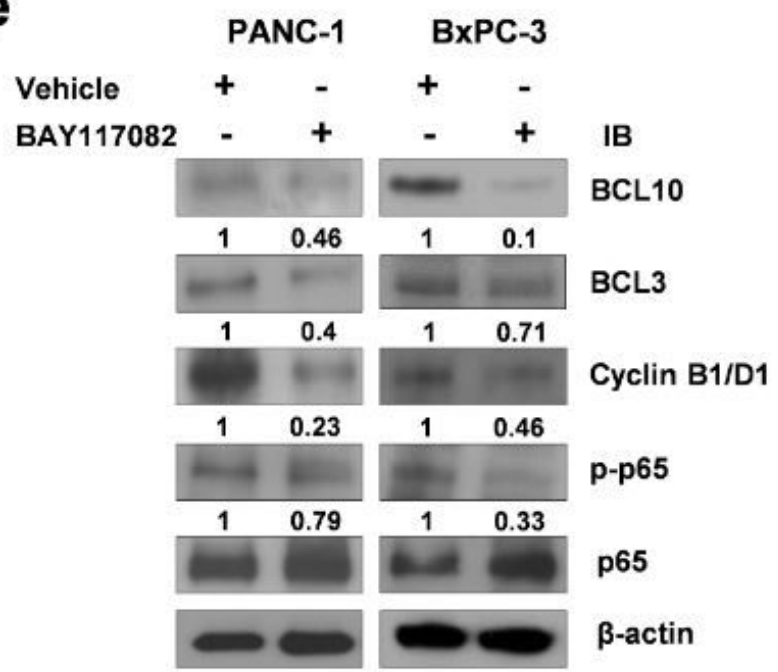

\section{Figure 3}

Inhibition of BCL10 downregulates cell cycle proteins expression and NF-KB activation in PDAC cell lines. a In total cell lysates, transfection with shBCL10 downregulated the expression of Cdc2 in PANC-1 cell lines and the expression of cyclin D1 in BxPC-3 compared to scrambled (Scr) group and control (Con) group. b shBCL10 transfection decreased the expressions of BCL3, c-Myc, p-IKBa, and NF-KB (p65) compared to scrambled (Scr) group and control (Con) group in nuclear lysates of both PANC-1 and BxPC3 cells. $\mathrm{c}$ The results from three independent experiments using shBCL10-transfected PANC-1 and BXPC-3 cells are presented as relative luciferase units (RLU) per milligram of protein (NF-KB-Luc promoter activityluciferase assay) (**, $p<0.01)$. d PANC-1 cells and BxPC-3 cells were treated with BAY117082 $(2 \mu \mathrm{M})$ for 
24 hours and compared with vehicle $\left(0.01 \%\right.$ DMSO) treated groups. ${ }^{*} p<0.05 ; n=3$. e PANC- 1 cells and BXPC-3 cells were treated as described in (d), the expressions of BCL10, BCL3, p-p65, and p65 in nuclear lysates of PANC-1 cells and BXPC-3 cells, and the expressions of cyclin B1 (PANC-1) and cyclin D1 (BXPC3) in total lysates were determined by western blotting. $\beta$-actin was used as the loading control. PDAC, pancreatic ductal adenocarcinoma.

A

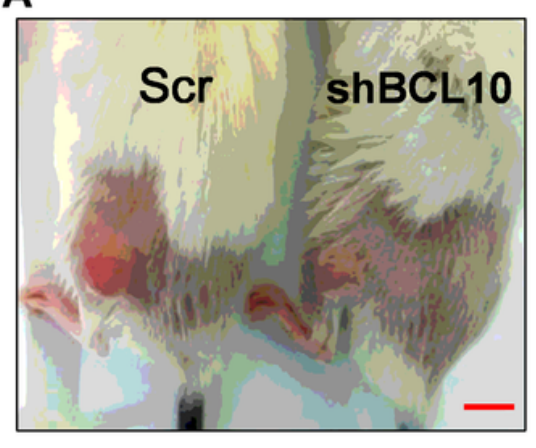

B
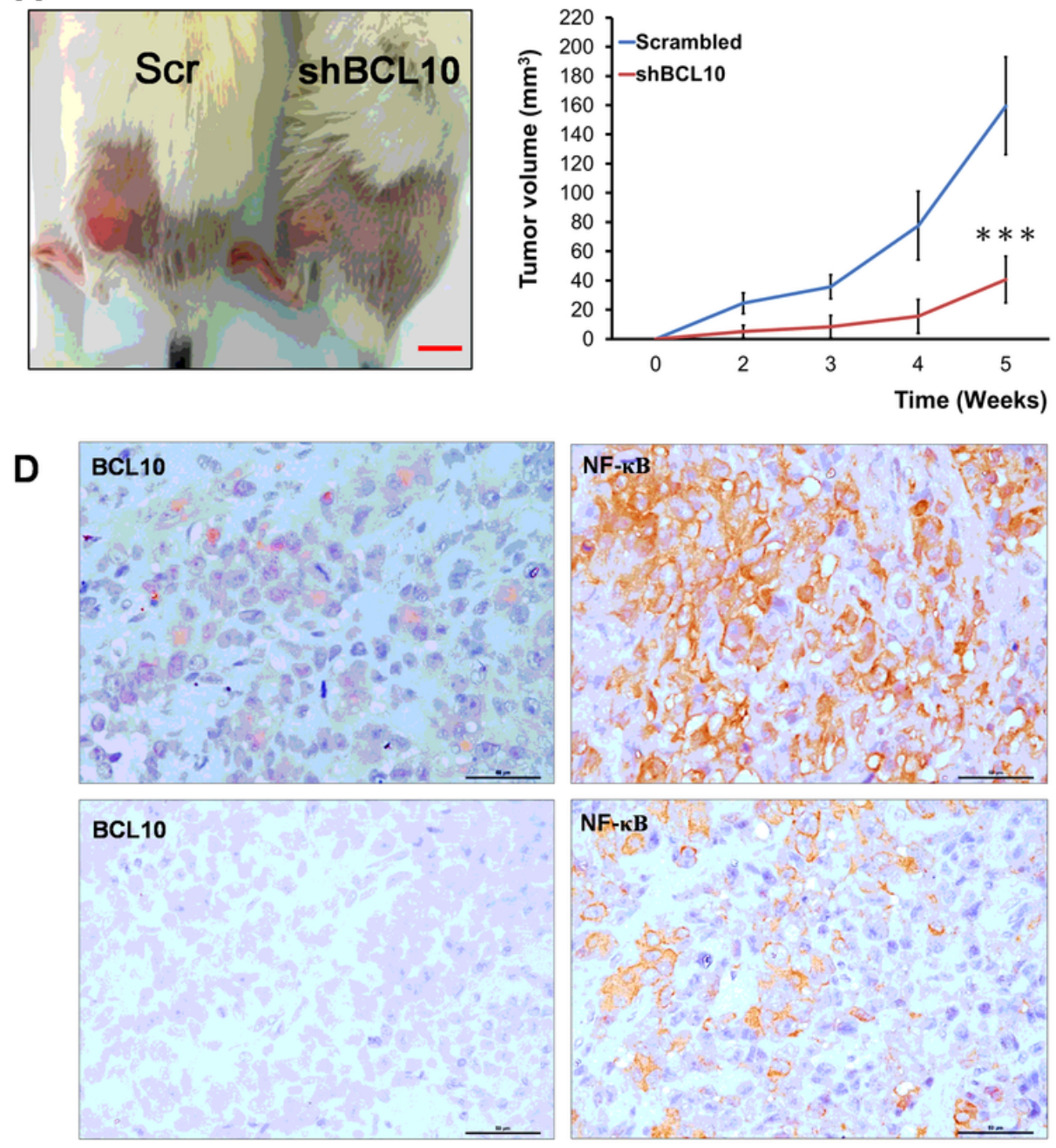
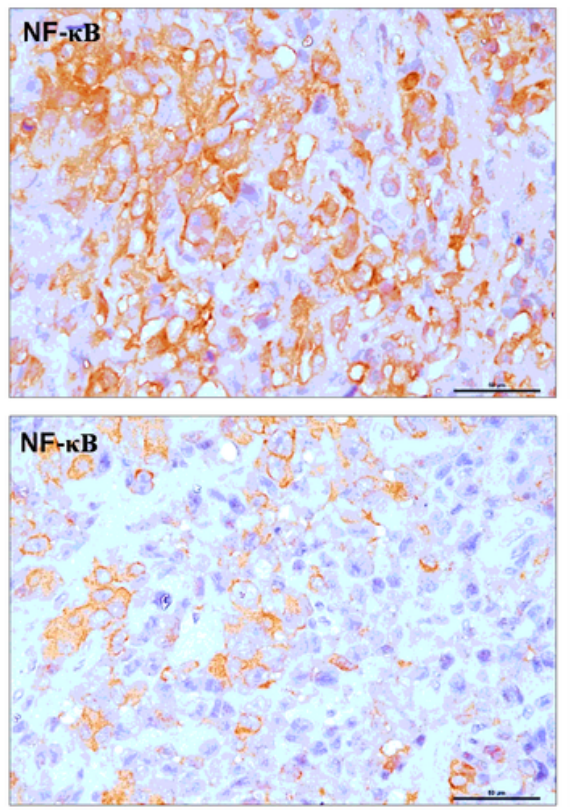

\section{C}

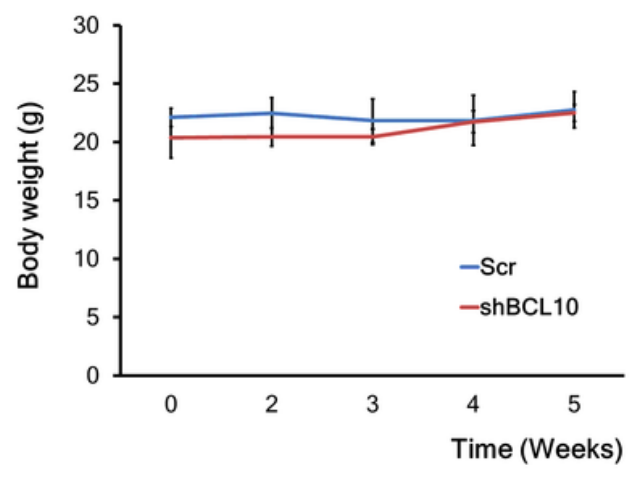

Figure 4
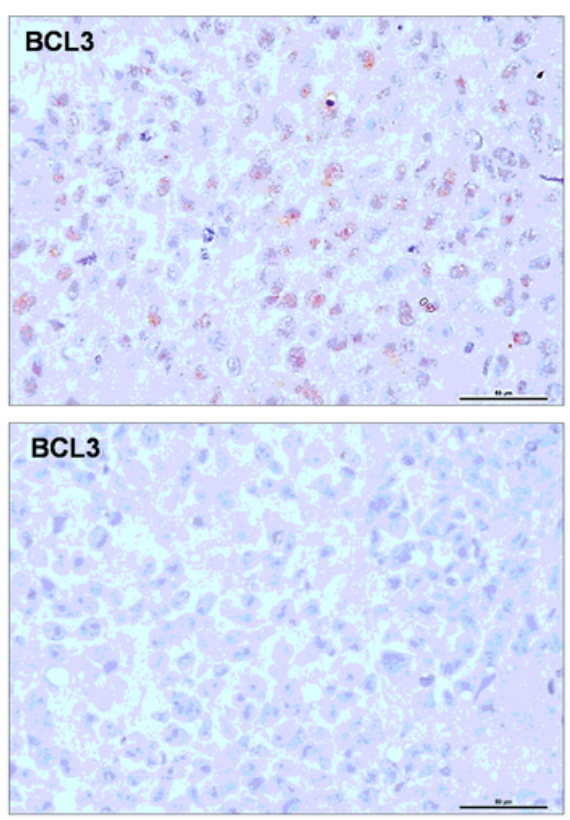

\section{Figure 4}

Silencing of BCL10 significantly inhibited tumor growth of PDAC in a xenograft model. a Approximately 1 $\times 106$ scrambled (Scr) PANC-1 cells and shBCL10-treated PANC-1 cells were implanted subcutaneously into both flanks of NOD/SCI D mice. Representative image shows that the xenograft tumor size was suppressed in shBCL10-treated group. Mice were sacrificed 6 weeks after implantation. Scale bar: 10 $\mathrm{mm}$. b The shBCL10-treated group resulted in $78 \%$ reduction of xenograft tumor volume compared with scrambled group. The results of tumor volume are expressed as $n=6$ in each treatment group and measured each week. ${ }^{\star \star \star} p<0.001$, compared to scrambled group. $c$ There is almost no difference in body weight between scrambled group and shBCL10-transfected group. $d$ The expression patterns of 
BCL10, BCL3, and NF-KB in tumor samples of PANC-1-xenograft model (upper panel, scrambled group; lower panel, shBCL10-treated group). PDAC, pancreatic ductal adenocarcinoma.
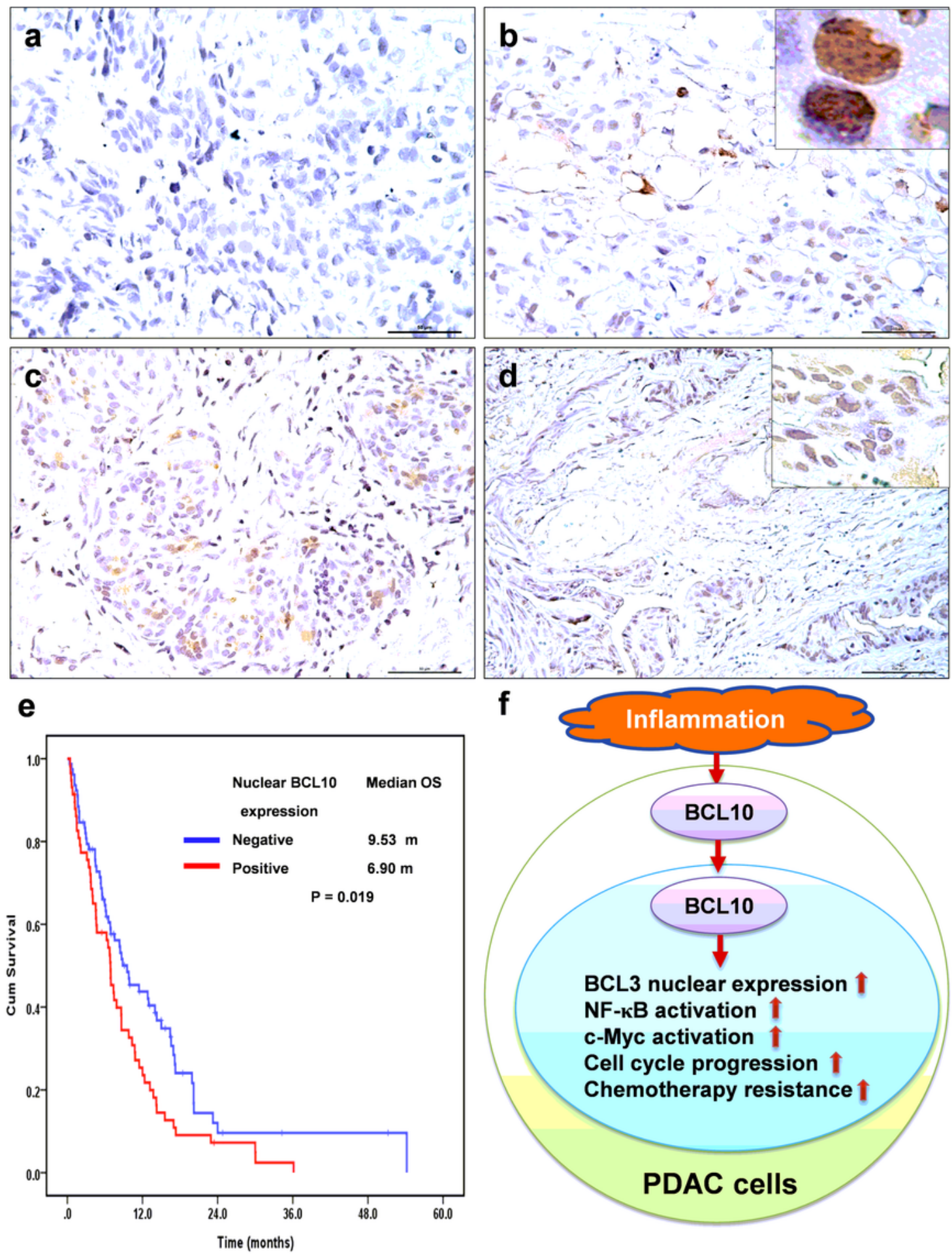

Fig. 5

Figure 5

Expression of nuclear BCL10 in tumor cells and its association with survival of patients with recurrent, advanced and metastatic PDAC. a Representative images of negative BCL10 expression in tumor specimens of PDAC. b Representative images of nuclear BCL10 expression in biopsy tumor specimens of 
PDAC. Right upper inset (nuclear expression of BCL10, 100X magnification). c Representative images of moderate nuclear BCL10 expression in tumor specimens of PDAC. $d$ Representative images of strong nuclear BCL10 expression in tumor specimens of PDAC. Right upper inset (nuclear expression of BCL10, 40X magnification). e The Kaplan-Meier overall survival (OS) for all patients associated with the expression of nuclear BCL10. $\mathrm{f}$ Inflammation-related signals in tumor microenvironment of PDAC upregulates BCL10 expressions and induces BCL10 nuclear translocation; and BCL10 nuclear expression results in BCL3 nuclear translocation and activation of NF-KB and c-Myc. These signaling pathways further promote cell cycle progression and contribute chemotherapy resistance of PDAC. PDAC, pancreatic ductal adenocarcinoma.

\section{Supplementary Files}

This is a list of supplementary files associated with this preprint. Click to download.

- SupplementaryFigure1.pdf

- SupplementaryTable1.docx 